\title{
The Design of Nanoscale Inorganic Materials with Controlled Size and Morphology by lonic Liquids
}

\author{
Elaheh Kowsari \\ Amirkabir University of Technology \\ Islamic Republic of Iran
}

\section{Introduction}

Recently, ionic liquids have successfully been employed in the preparation of inorganic materials (Antonietti et al., 2004, Taubert \& Li, 2007). Ionic liquids often act as solvents, reactants or morphology templates, which enable the synthesis of inorganic materials with novel morphologies or improved properties. So far only a handful of studies have reported on the fabrications of nano- or micro-scaled materials including particles of metal oxide (Ding et al., 2007, Bühler \& Fledmann, 2006) and sulfide (Jiang, et al., 2005, Jiang \& Zhu, 2005). Many metal nanoparticles (NPs) such as Ir (Bühler \& Fledmann, 2006), Rh (Wang \& Zhu, 2005), Ru (Jiang, et al., 2005), Te (Jiang \&. Zhu, 2005), Al (Mu, et al., 2004), Ag (Zhu et al., 2004), Pt (Foneca et al., 2003), and Au (Dupont et al., 2002) have been prepared in the presence of ionic liquids.

Novel nanostructures can be produced by selecting suitable ionic liquid reaction systems: $\mathrm{TiO}_{2}$ (Nakashima \& Kimizuka, 2003, Yoo et al., 2004, Zhou \& Antonietti, 2003), Te nanorods (Zhu et al., 2004), Si (Abedin et al., 2004), CoPt nanorods (Wang \&Yang, 2005), and porous silica (Zhou, et al., 2004, Zhou \& Antonietti, 2004) have recently been synthesized, as reported. Žilkova' et al. have used 1-methyl-3-octylimidazolium chloride $\left(\mathrm{C}_{8} \mathrm{mimCl}\right.$, an ionic liquid) as a template to prepare $\mathrm{\gamma}^{-} \mathrm{Al}_{2} \mathrm{O}_{3}$ from the hydrolysis and condensation of $\mathrm{Al}_{2} \mathrm{Cl}(\mathrm{OH})_{5}$ (Žilková, et al., 2006). It was shown that the molar ratio of $\mathrm{Al} / \mathrm{C}_{8} \mathrm{mimCl}$ was important to define the porosity, i.e. the framework or textural type. Mumalo-Djokic and coworkers have put forward the concept of "all-in-one" solvent-reactant(-template)s, (Taubert \& Li, 2007, Taubert 2004), that is ionic liquids or ionic liquid crystals (Binnemans, 2005) that are at the same time the solvent, the reactant, and the template for the fabrication of an inorganic. These special systems have been termed ionic liquid precursors and ionic liquid crystal precursors respectively (Taubert 2004, Zhu et al., 2006). Ionic liquid crystal precursors allow for the controlled mineralization of inorganics with complex structure and morphology. For example, they have made $\mathrm{CaF}_{2}$ tubes, $\mathrm{CuCl}$ platelets, and $\mathrm{Au}$ platelets from ionic liquid crystal precursors or their crystalline analogues (Taubert 2004, Taubert et al., 2007, Taubert et al., 2006, Taubert et al., 2005, Taubert 2005). Furthermore, other research groups have extended this concept of reactive ionic liquid crystals to other compounds (Zhu et al., 2006, Dobbs et al., 2006, lee et al., 2006, Kem et al., 2006). 
Although there are a few inspiring short accounts or perspectives focused on selected topics in materials synthesis using ionic liquids, a relatively comprehensive and updated review of this subject is still a gap, especially considering that the field is growing quite fast. Therefore, in the present contribution, the use of ionic liquids in the preparation of different categories of inorganic materials, including silicas, open framework structures, and ionic liquid-modified materials using ionic liquids by different methods, is systematically reviewed. Due to the abundance of research reported in the literature, the present chapter dealt only with some typical examples and key concepts proposed as highlights.

\section{Methods}

\subsection{Sonochemical synthesis}

Ionic liquids have favorable intrinsic properties that make them of interest as solvents for various chemical reactions. The same properties that make the liquids effective solvents also make them interesting liquids for studies involving sonochemistry, acoustic cavitation, and sonoluminescence (Suslick et al., 1991, Suslick, 1988). Recent interest in using ultrasound to accelerate chemical reactions conducted in ionic liquids necessitates an understanding of the effects of acoustic cavitation on these solvents (Flannigan et al., 2005).

The use of ultrasonic irradiation for producing nanomaterials has been a research topic of great interest (Dhasn et al., 1999). This is due to the simplicity of sonochemical method, the cheap price of the equipment and that in many cases the as-prepared material is obtained in the crystalline phase. The ultrasonic-assisted aqueous room temperature ionic liquid method was applied to prepare zinc sulfide and zinc oxide nanomaterials (Zheng et al. 2010; Jia et al. 2010), among many other nanomatreials. Selection of the room temperature ionic liquid was mainly based on the fact that it can be obtained at a relatively low price and the method for its synthesis is simple.

Nanosheet-based microspheres of $\mathrm{ZnO}$ with hierarchical structures were prepared by ultrasonic irradiation in acidic ionic liquids by Kowsari (Kowsari 2010). It is found that the ultrasonic irradiation time, ultrasonic frequency, and the acidic ionic liquids influence the growth mechanism and optical properties of $\mathrm{ZnO}$ nanostructures. By changing the type of acidic ionic liquids, ultrasonic irradiation time, ultrasonic frequency optical properties of $\mathrm{ZnO}$ nanostucture are manageable. The photocatalytic activity test results indicate that the hollow spheres-like $\mathrm{ZnO}$ nanophotocatalysts have good photocatalystic activities. Overall, the cited results indicate that the prepared $\mathrm{ZnO}$ nanophotocatalysts show good photocatalystic activity and can be considered as a promising photocatalyst for dyes wastewater treatment. Fig. 1 . shows the precursor composed of plate-like nanostructures with edge thicknesses of bout 40 $\mathrm{nm}$ and smooth surfaces. The structures synthesized in this experiment can indicate a new way to construct nanodevices by self-organization in one step.

In other report, flower like $\mathrm{ZnO} / \mathrm{MgO}$ nanocomposites were prepared by ultrasonic irradiation and chiral ionic liquid, ditetrabutylammonium tartarate, [TBA $]_{2}[\mathrm{~L}-\mathrm{Tar}]$. It is found that the ultrasonic frequency, the ultrasonic irradiation time and the chiral ionic liquid influence the growth mechanism and optical properties of $\mathrm{ZnO} / \mathrm{MgO}$ nanocomposites. Enhancement of bandgap in the $\mathrm{ZnO} / \mathrm{MgO}$ nanocomposites, due to morphology effect, was an interesting observation. The effect of the ultrasonic irradiation time on $\mathrm{ZnO} / \mathrm{MgO}$ nanocomposites morphology (in the presence of chiral ionic liquid) is shown in Fig 2. As it can be observed in Fig 2, when the ultrasonic irradiation time increases, the thickness of the nanosheets making the flowerlike is reduced. Therefore, the morphology takes a more arranged shape. 

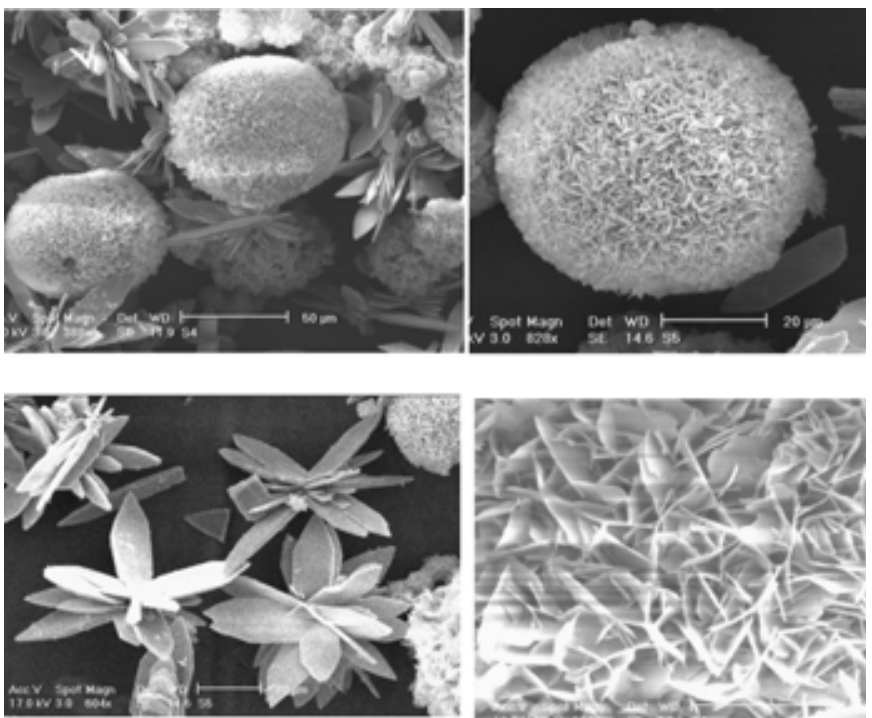

Fig. 1. Regular hollow spherical, composed of a number of nanosheets, with an average size of 50-70 $\mu \mathrm{m}$. and leaf-like $\mathrm{ZnO}$ nanostructure, synthesis by acidic ionic liquid, [(mim) hex(mim)][2 $\left.\mathrm{H}_{2} \mathrm{PO}_{4}\right]$ (kowsari (2010), accepted for presentation ${ }^{\text {nd }}$ Asia Pacific Conference on Ionic Liquids and Green Processes September 7-10 , 2010 Dalian • China)

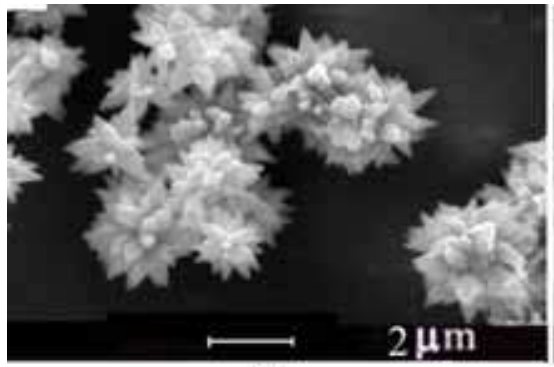

(a)

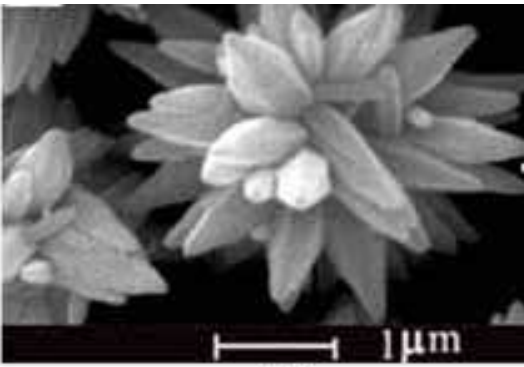

(b)

Fig. 2. The effect of ultrasonic irradiation time on the evolution of the morphologies of $\mathrm{ZnO} / \mathrm{MgO}$ nanocomposite, (a) $2 \mathrm{~h}$ and (b) $2.5 \mathrm{~h}$, (Ultrasonic frequencies $=40 \mathrm{kHz}$, The ultrasonic power was kept at $200 \mathrm{~W}$ ) (kowsari (2010), accepted for presentation $2^{\text {nd }}$ Asia Pacific Conference on Ionic Liquids and Green Processes September 7-10 , 2010 Dalian (China)

\subsection{Sol-gel synthesis}

A good number of works concerning the synthesis of inorganic nanomaterials are based on sol- gel route. The original use of ionic liquids as solvents for inorganic sol-gel reactions is the acid-catalyzed sol-gel synthesis of silica aerogels (Dai et al., 2003). It turned out that such aerogels can be dried without a supercritical drying procedure. Subsequently, 1-butyl3-methylimidazolium hexafluorophosphate $\left[\mathrm{BMIM}^{2}\left[\mathrm{PF}_{6}\right]\right.$ was used to synthesize hollow $\mathrm{TiO}_{2}$ microspheres by interfacial sol-gel reaction (Nakashima \& Kimizuka, 2003). 
Zhou, et al. used $\mathrm{TiCl}_{4}$ as the precursor to synthesize very small $\mathrm{TiO}_{2}$ nanocrystals in [BMIM] $\left[\mathrm{BF}_{4}\right]$ and obtained mesoporous spherical aggregates of $\mathrm{TiO}_{2}$ nanocrystals (Zhou \& Antonietti, 2003). The synthesized titania aggregates exhibits structural mesoporosity with considerable high surface area and narrow pore size distribution, rendering the materials interesting for solar cell conversion, catalysis, and electronic devices. Smarsly, et al. synthesized rutile nanostructures at low temperature by sol-gel chemistry in 1-ethyl-3methylimidazolium bis(trifluoromethylsulfonyl) imide (Kaper et al., 2003).

\subsubsection{Synthesis $\mathrm{Y}_{2} \mathrm{O}_{3}$ nano-/microstructured phosphors without metal activators fabricated using functionalized ionic liquids}

Flowerlike $\mathrm{Y}_{2} \mathrm{O}_{3}$ nano-/microstructured phosphors without metal activators were fabricated by an ionic liquid assisted method (acid-catalyzed sol-gel synthesis) involving temperature $\left(600{ }^{\circ} \mathrm{C}\right)$ annealing by Kowsari and Faraghi (Kowsari \& Faraghi, 2010). Also, the effect of ionic liquid concentration on the morphology of the product was investigated. The results revealed that the ionic liquid s play a crucial role in the formation of various morphologies of $\mathrm{Y}_{2} \mathrm{O}_{3}$. The effect of the ionic liquid $\mathrm{s}$ cation and the counter anions on the $\mathrm{Y}_{2} \mathrm{O}_{3}$ morphology of these nanostructures were studied experimentally. It was observed that $\mathrm{Y}_{2} \mathrm{O}_{3}$ morphology and PL of these nanostructures was strongly influenced by the type of cation and anion. As the length of the subsidiary chain of cation section of ionic liquid (imidaziole ione) reduces, the thickness of the nano-sheets increases. Since $\mathrm{Y}^{3+}$ itself is non-luminous, the observed luminescence from the $\mathrm{Y}_{2} \mathrm{O}_{3}$ samples must be related to chemical-bond breakage with resultant carbon formation and/or non-stoichiometry (from ionic liquid) created by the oxygen deficiency in the system.

In this study, ionic liquid was used as a templating agent and produce different morphologies. The structures of ionic liquids show in Fig.3.

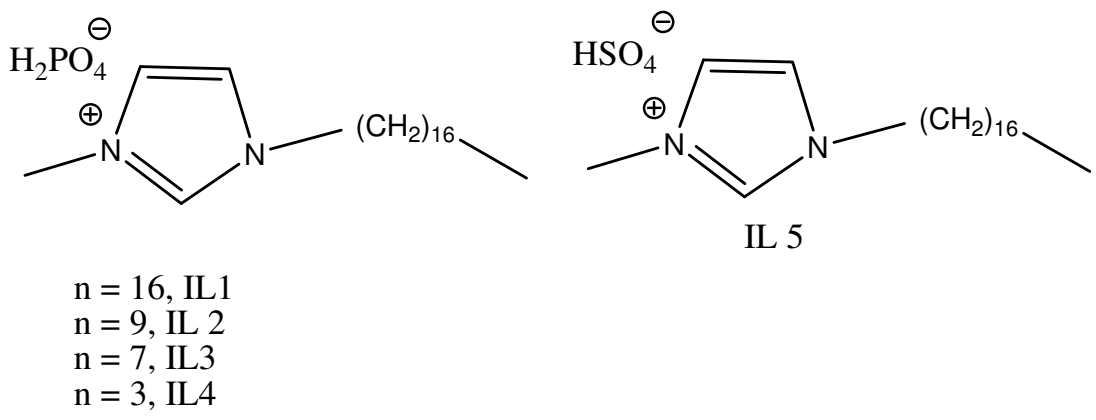

Fig. 3. Structures of ionic liquids (Reproduced from Kowsari \& Faraghi, (2010) Materials reserch Bull 45, 8, 939-945, Copyright (2010), with permeation from Elsevier)

Here, the effect of ionic liquid concentration on the morphology of the product was investigated. Fig. 4 shows SEM photographs of products prepared with different ionic liquid concentrations. The results demonstrate that the concentration of ionic liquid is an important factor with regard to the formation of novel of $\mathrm{Y}_{2} \mathrm{O}_{3}$ microstructures. Since no surfactant or capping agent was employed in this synthesis, the ionic liquid used is believed to play an important role in the formation of the novel structure. 


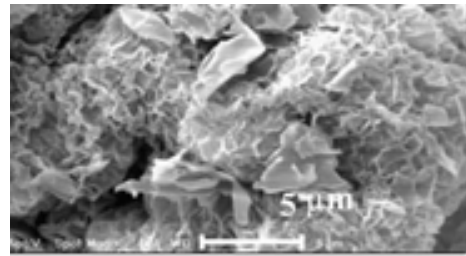

(a)

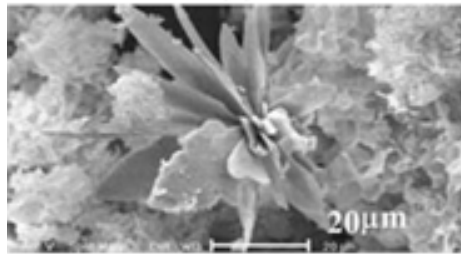

(c)

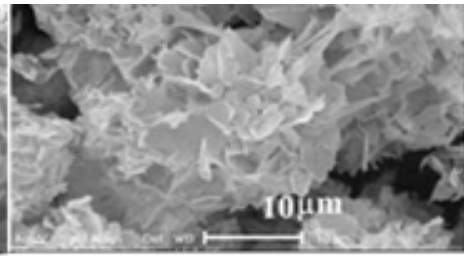

(b)

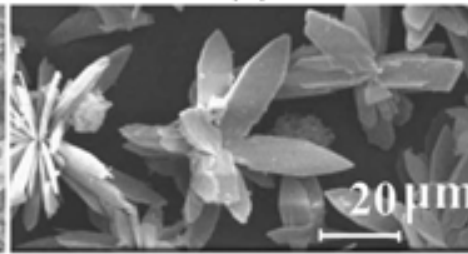

(d)

Fig. 4. SEM images showing the morphological evolution of of $\mathrm{Y}_{2} \mathrm{O}_{3}$ samples with different concentrations of IL1: (a) 0.036(b) 0.027 M, (c) 0.018 M, and (d) 0.012 M, (Reproduced from Kowsari \& Faraghi, (2010) Materials reserch Bull 45, 8, 939-945, Copyright (2010), with permeation from Elsevier)

In high concentration of ionic liquid, $(0.045 \mathrm{mmol})$ the $\mathrm{Y}_{2} \mathrm{O}_{3}$ sample is irregular and crossed microsheets which overlap each other. When $0.012 \mathrm{mmol}$ of ionic liquid is added in hydrothermal solution, the $\mathrm{Y}_{2} \mathrm{O}_{3}$ sample is shaped as a uniform flowerlike architecture, as shown in Fig. 4c.

The formation mechanism of $\mathrm{Y}_{2} \mathrm{O}_{3}$ flowers is obviously due to the templating effect in the present ionic liquid- water reaction system. The inset SEM images in Fig. 4e offer a clear view of the morphology from which it can be seen that the flowerlike $\mathrm{Y}_{2} \mathrm{O}_{3}$ architecture is built up from $\mathrm{Y}_{2} \mathrm{O}_{3}$ nanoflakes. The results suggested that the morphology of the $\mathrm{Y}_{2} \mathrm{O}_{3}$ sample prepared by the solution-phase reactions is influenced by adding ionic liquid. The $\left[\mathrm{C}_{17} \mathrm{mim}\right]+$ cation of $\left[\mathrm{C}_{17} \mathrm{mim}\right]^{+}\left[\mathrm{H}_{2} \mathrm{PO}_{4}^{-}\right]$has a hydrophobic chain which, under proper experimental conditions $\left[\mathrm{C}_{17} \mathrm{mim}\right]^{+}$, could form micells with the positive ends stretch to the outside. After the $\mathrm{Y}\left(\mathrm{NO}_{3}\right)_{3}$ is solved in water in the absence of $\left[\mathrm{H}_{2} \mathrm{PO}_{4}\right]^{-}$, which is an ionic liquid anion, there is the possibility of formation of $\left[\mathrm{Y}\left(\mathrm{H}_{2} \mathrm{O}\right)_{2}\left(\mathrm{NO}_{3}\right)_{3} \mathrm{H}_{2} \mathrm{PO}_{4}\right]^{-}$. Then, $\left[\mathrm{C}_{17} \mathrm{mim}\right]^{+}$, which is ionic liquid cation, can interact with precursor $\left[\mathrm{Y}\left(\mathrm{H}_{2} \mathrm{O}\right)_{2}(\mathrm{NO})_{3} \mathrm{H}_{2} \mathrm{PO}_{4}\right]^{-}$ ions through electrostatic attraction. Therefore, flowerlike $\mathrm{Y}_{2} \mathrm{O}_{3}$ architecture can be obtained by hydrothermal route by adding a small amount of $\left[\mathrm{C}_{17} \mathrm{mim}\right]^{+}\left[\mathrm{H}_{2} \mathrm{PO}_{4}\right]^{-}$

To further confirm the existence of the carbon impurity, the sample $\mathrm{Y}_{2} \mathrm{O}_{3}-300$, temperature $\left(30{ }^{\circ} \mathrm{C}\right)$ annealing, was subjected to XPS analysis, which is a powerful tool for determining the surface composition of a material qualitatively. Fig. 5 shows the XPS analysis results of the sample. Signals of bonding energy from the $\mathrm{Y}\left(3 \mathrm{~d}_{5 / 2}, 158.4 \mathrm{ev}, \mathrm{O}(1 \mathrm{~s}, 532.1 \mathrm{eV}), \mathrm{C}(1 \mathrm{~s}\right.$, $285.0 \mathrm{eV}$ ), and N (1s, $399.0 \mathrm{eV}$ ) can be seen clearly in Fig. 10 (Wang \& Ong, 2007, Ramı́rez et al., 2002) This provides additional evidence for the existence of the carbon impurity.

In this study, some $\mathrm{Y}_{2} \mathrm{O}_{3}$ nanostructures were prepared in the presence of other ionic liquid $\mathrm{s}$ with different cations, and anions each at a concentration of $0.027 \mathrm{M}$. The Effect of the ionic liquid s cation and the counter anions on the $\mathrm{Y}_{2} \mathrm{O}_{3}$ morphology of these nanostructures were studied experimentally. It was observed that $\mathrm{Y}_{2} \mathrm{O}_{3}$ morphology and $\mathrm{PL}$ of these nanostructures was strongly influenced by the type of cation and anion. As the length of the 

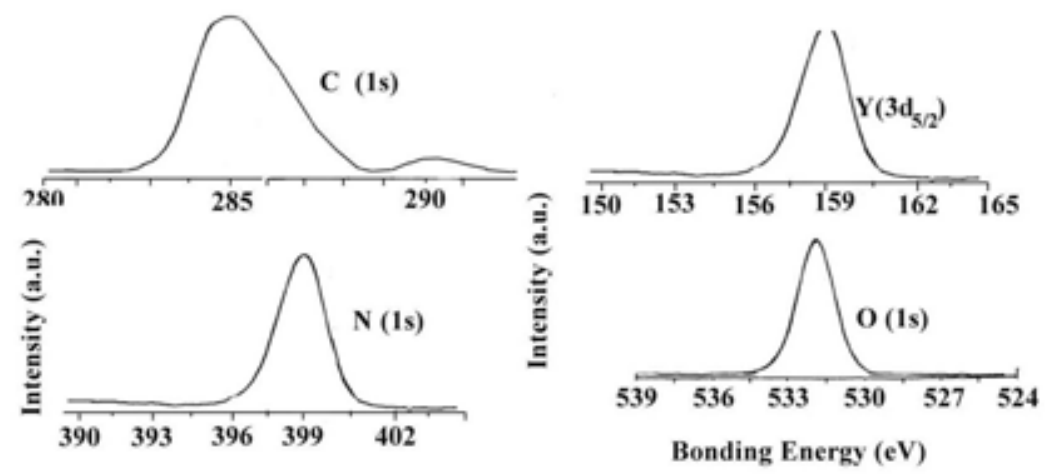

Fig. 5. XPS spectra of $\mathrm{Y}_{2} \mathrm{O}_{3}-300$ sample (Reproduced from Kowsari \& Faraghi, (2010) Materials reserch Bull 45, 8, 939-945, Copyright (2010), with permeation from Elsevier)

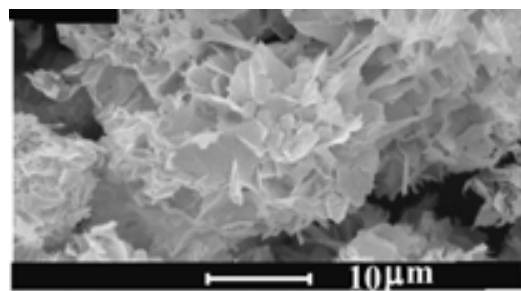

(a)

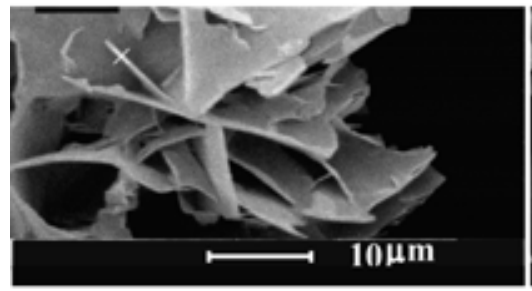

(b)

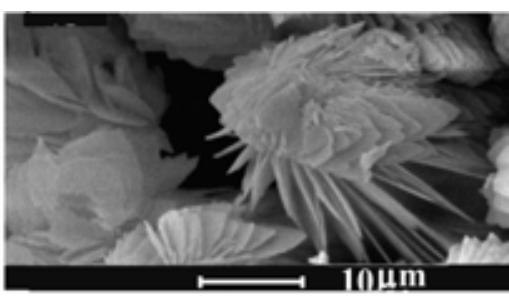

(c)

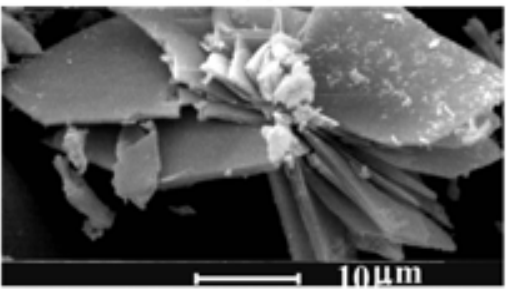

(d)

Fig. 6. SEM images showing the morphological evolution of $\mathrm{Y}_{2} \mathrm{O}_{3}$ samples with different cation and anion of ionic liquids, [concentrations of IL = 0.027 M]: (a) IL1, (b) IL2, (c) IL3 and (d) IL4 [ IL1, $\left(\left[\mathrm{C}_{17} \mathrm{mim}\right]^{+}\left[\mathrm{H}_{2} \mathrm{PO}_{4}\right]^{-}\right.$, 1-heptadecyl-3-methylimidazolium dihydrogen phosphate), IL2, ([ $\left.\mathrm{C}_{10} \mathrm{mim}\right]^{+}\left[\mathrm{H}_{2} \mathrm{PO}_{4}\right]^{-}, 1$-decyl-3-methylimidazolium dihydrogen phosphate), IL3, ([C $\left.\mathrm{C}_{8} \mathrm{mim}\right]^{+}\left[\mathrm{H}_{2} \mathrm{PO}_{4}\right]^{-}$, 1-octyl-3-methylimidazolium dihydrogen phosphate), IL4, $\left(\left[\mathrm{C}_{4} \mathrm{mim}\right]^{+}\left[\mathrm{H}_{2} \mathrm{PO}_{4}\right]^{-}\right.$, 1-buthyl-3-methylimidazolium dihydrogen phosphate)]. (Reproduced from Kowsari \& Faraghi, (2010) Materials reserch Bull 45, 8, 939-945, Copyright (2010), with permeation from Elsevier)

subsidiary chain of cation section of ionic liquid (imidaziole ione) reduces, the thickness of the nano-sheets increase. And as anion section of ionic liquid changes $\left(\mathrm{H}_{2} \mathrm{PO}_{4^{-}}\right.$to $\left.\mathrm{HSO}_{4}^{-}\right)$, as shown is Fig. 6, morphology changes from a nano-sheet-like structure to a coral-like one. Since $\mathrm{Y}^{3+}$ itself is non-luminous, the observed luminescence from the of $\mathrm{Y}_{2} \mathrm{O}_{3}$ samples must be related to chemical-bond breakage with resultant carbon formation and/or non- 
stoichiometry created by the oxygen deficiency in the system (Fujimaki et al., 1997, Green, 1997, Pifferi et al., 1997, Hayakawa et al., 2003). Here, we assume that the carbon-related impurities play a key role in the luminescence of of $\mathrm{Y}_{2} \mathrm{O}_{3}$.

\subsubsection{Morphogenesis and crystallization of $\mathrm{Bi}_{2} \mathrm{~S}_{3}$ nanostructures by an ionic liquid- assisted templating route}

An ionic liquid 1-butyl-3-methylimidazolium tetrafluoroborate ([BMIM][BF $]$ ) solution system has been designed for the morphogenesis and crystallization of $\mathrm{Bi}_{2} \mathrm{~S}_{3}$ nanostructures at low temperature and ambient atmosphere by Jiang et al. (Jiang et al., 2005).

Uniform $\mathrm{Bi}_{2} \mathrm{~S}_{3}$ flowers with a size of 3-5 $\mu \mathrm{m}$, which are composed of nanowires with a diameter of $60-80 \mathrm{~nm}$, can be prepared in large scale by the template effect of the ionic liquid solution, in which vesicles are formed as confirmed by laser light scattering analysis. With prolonged aging time, the flowerlike structures tend to become loose and fall off from the mother flowers, and finally the individual nanowires will form.

The results demonstrated that the shape evolution and phase transformation strongly depend on the reaction conditions, such as $\mathrm{pH}$ value, reaction temperature, and reaction time. The $\mathrm{pH}$ value of the reaction medium plays a key role in the present procedure for the synthesis of $\mathrm{Bi}_{2} \mathrm{~S}_{3}$ nanoflowers. First, a suitable $\mathrm{pH}$ value can effectively prevent $\mathrm{BiCl}_{3}$ hydrolysis to $\mathrm{BiOCl}$ in the initial reaction stage and kinetically control the growth rate of dendrite $\mathrm{Bi}_{2} \mathrm{~S}_{3}$ nanostructures. When the $\mathrm{pH}$ value is about 2 , even within a short period, for example,about half an hour, large-scale and uniformly shaped $\mathrm{Bi}_{2} \mathrm{~S}_{3}$ nanoflowers with a size of $3.5 \mu \mathrm{m}$ can be prepared conveniently (Fig. 7).

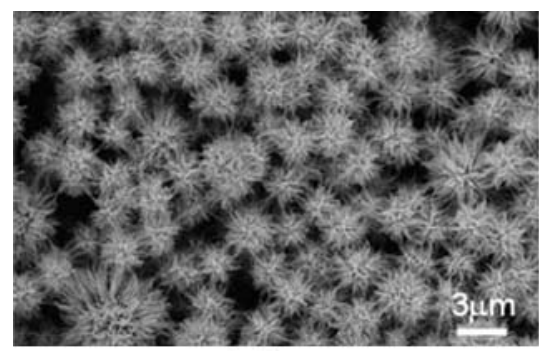

(a)

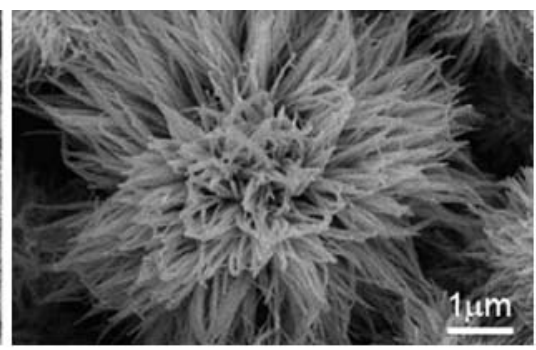

(b)

Fig. 7. SEM images of the product obtained in an ionic liquid system after reaction at $120^{\circ} \mathrm{C}$ for 0.5 h. Starting $\mathrm{pH}=2$ ) (Reproduced from Jiang et al. Chem. Mater. 2005, 17, 6094-6100, Copyright (2009), with permeation from American Chemical Society)

\subsection{Thermal synthesis}

\subsection{1 lonothermal synthesis}

Ionic liquids are known for their nonvolatile, nonflammable, and thermally stable properties. These properties make the reactions in open reactor possible. The term "ionothermal" has been used to describe reactions that are conducted in ionic liquids at high temperature with ambient pressures. As a result, ionothermal reactions avoid high pressure of hydrothermal or solvothermal reactions and eliminate safety problems related to high pressure (Taubert \& Li 2007). Cooper, et al. have demonstrated that imidazolium-based 
ionic liquids can be utilized to synthesize several phosphate-based microporous zeolites by an ionothermal process (Cooper et al., 2004), Dai, et al. reported the use of a newly developed ionic liquid system containing zinc metal ions, which can serve as both solvents and metal-oxide precursors, for manufacturing nanostructured zinc oxide under the ionothermal condition ( $\mathrm{Zhu}$ et al., 2006). The morphologies of $\mathrm{ZnO}$ are strongly dependent on the nature of the ionic liquid precursor (ligands), providing unique methodologies to control the growth conditions.

In ionothermal synthesis, the ionic liquid acts as the solvent, and in many cases also as a template provider playing a structure-directing role in the formation of zeolites and openframework structures. The use of [EMim][Br] led to the formation of open-framework aluminophosphates SIZ-1, SIZ-3, SIZ-4, SIZ-5, and SIZ-6, (Cooper et al. 2004; Parnham et al. 2006) and the use of choline chloride/urea mixtures led to SIZ-2 and AlPO-CJ2 (Cooper et al. 2004). The ionic liquids acted as both solvent and template provider.

\subsubsection{Hydrothermal synthesis}

Several research groups have employed ionic liquids for the synthesis of nanostructures by hydrothermal method. Zhang and coworkers (Zhang et al. 2008) reported a hydrothermal method to synthesize sheaf-like $\mathrm{CuO}$ self-assembled by nanoplatelets in [BMIM]BF 4 . [BMIM] $\mathrm{BF}_{4}$ was used as a cosolvent and modifiers in the formation of sheaflike $\mathrm{CuO}$. Hollow molybdenum disulfide (MoS2) microspheres were synthesized in ionic liquids (1butyl-3- methylimidazolium chloride, [BMIM]Cl)/water binary emulsions using the hydrothermal method at $180{ }^{\circ} \mathrm{C}$ by Luo and coworker (Lue et al. 2008). Liu and coworkers (Liu et al. 2009) have also reported a modified hydrothermal method for the synthesis of CdSe nanoparticles-assembled microspheres with macropores using 1-n-butyl-3methylimidazolium bromide $([\mathrm{Bmim}] \mathrm{Br})$ to assist the reaction. By changing the processing parameters, they fabricate wurtzite CdSe microspheres with an average diameter of about 3 $\mu \mathrm{m}$. The possible growth mechanismof the CdSe microspheres is investigated.

Nanostructured $\mathrm{ZnO}$ was synthesized by a hydrothermal route using different ionic liquids as the morphology templates by Yavari et al. (Yavari e.tal 2009). The morphology of ZnO changes from rod-like to star-like and flower-like in different ionic liquids. A 3D nano/micro structure $\mathrm{ZnO}$ with unique flower-like morphology has been synthesized (Fig. 9) via the assembly of dicationic ionic liquid and $\left[\mathrm{Zn}(\mathrm{OH})_{4}\right]^{2-}$.

A typical SEM image of an individual $\mathrm{ZnO}$ hexagonal prism with hexagonal pyramid in tip is presented in Fig. 10. It is indicated that it can grow along the [0001] direction.

It has been known that the adsorption of growth units on crystal surfaces strongly affects the growth speed and orientation of crystals ( $\mathrm{Li}$ et al., 1999). When a $\mathrm{ZnO}$ crystal grew, an ionic liquid (with pyridinium cation, for example) film could form at the interface between solution and the crystal. This landing process on the surface of $\mathrm{ZnO}\left[\begin{array}{llll}0 & 0 & 0 & 1\end{array}\right]$ crystal face is shown graphically in Fig. 11. Since ionic liquid favors to form a film in which molecules tend to be perpendicular to the absorbed surface, the growth units would tend to face-land onto the growing interface as shown in Fig. 11. This kind of landing and dehydration will result in three $\mathrm{Zn}-\mathrm{O}-\mathrm{Zn}$ bonds, which make it predominant in competition with vertex- and edge-landing. Thus, the $\mathrm{ZnO}$ crystals should grow preferentially along the c-axis $\left(\left[\begin{array}{llll}0 & 0 & 0 & 1\end{array}\right]\right.$ direction) as this kind of face-landing on $\left[\begin{array}{llll}0 & 0 & 0 & 1\end{array}\right]$ crystal face and the following dehydration steps are repeated (Li et al., 1999). 

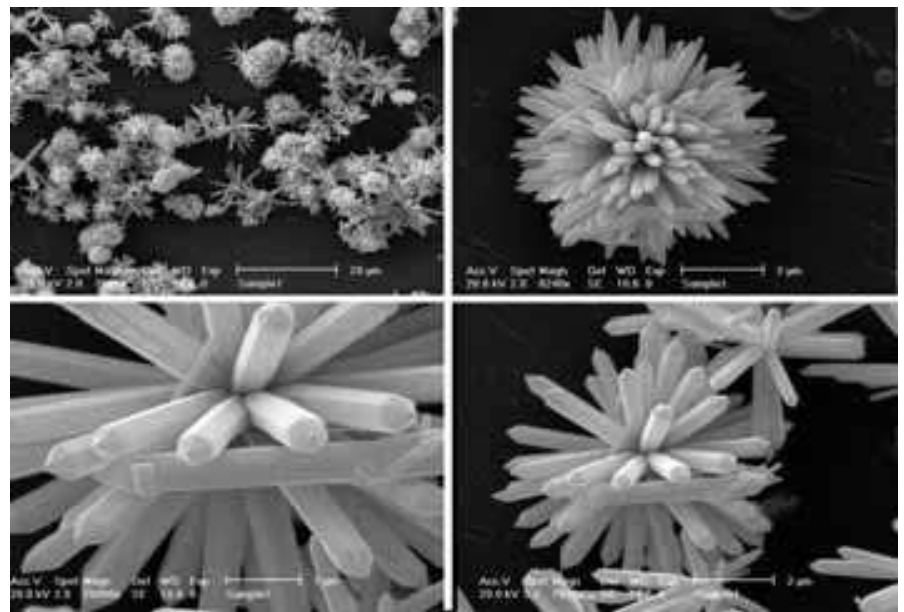

Fig. 9. SEM image of the flower-like $\mathrm{ZnO}$ in $\left[\left(\mathrm{C}_{1}\right)_{2} \mathrm{C}_{8}(\mathrm{im})_{2}\right](\mathrm{Br}-)_{2}$, mole ratio $\mathrm{OH}-/ \mathrm{Zn}^{+2}=$ $30: 1$ and $\left[\left(\mathrm{C}_{1}\right)_{2} \mathrm{C}_{8}(\mathrm{im})_{2}\right](\mathrm{Br}-)_{2,}=0.10 \mathrm{~g}$. (Reproduced from Yavari et al. (2009) J. Nanopart. Res.; 11, 861, Copyright (2009), with permeation from Springer)

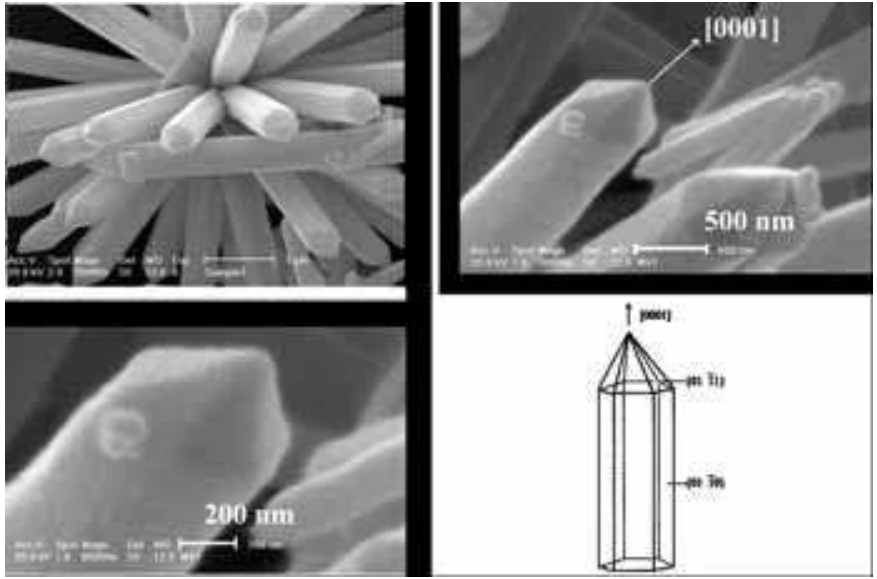

Fig. 10. A typical SEM image of an individual $\mathrm{ZnO}$ hexagonal prism with hexagonal pyramid in tip (Reproduced from Yavari et al. (2009) J. Nano part. Res.; 11, 861, Copyright (2009), with permeation from Springer)

According to the process described earlier, it is supposed that ionic liquid leads to the orientation growth of $\mathrm{ZnO}$ rods. Similarly, $\mathrm{ZnO}$ flower-like assemblies can be formed in the presence of ionic liquid which has two identical imidazolium cations.

The $\mathrm{ZnO}$ has been found to exhibit sensitivity to $\mathrm{C}_{2} \mathrm{H}_{5} \mathrm{OH}, \mathrm{NH}_{3}$ and other species However, the $\mathrm{ZnO}$ based sensing devices possess several critical limitations, which are difficult to overcome, such as a limited maximum sensitivity and the operation at high temperature $\left(400-500^{\circ} \mathrm{C}\right)$. Flower-like $\mathrm{ZnO}$ nanostructures improves performance such as sensitivity and working temperature (room temperature). 

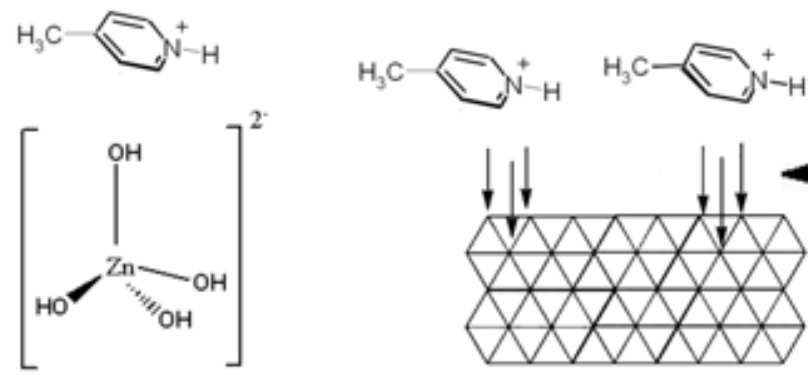

Fig. 11. (a) Schematic illustration of ion-pair formed between ionic liquid and $\left[\mathrm{Zn}(\mathrm{OH})_{4}\right]^{-2}$; (b) landing process on the surface of $\mathrm{ZnO}$ [0001] crystal face by ionic liquid . (Reproduced from Yavari et al. (2009) J. Nanopart. Res.; 11, 861, Copyright (2009), with permeation from Springer)

Flower-like ZnO morphology, with different shapes, have been synthesized via a novel and environment-friendly hydrothermal method using zinc acetate and a task specific dicationic dibasic ionic liquid, [mmpim $]_{2}[\mathrm{OH}]_{2}$, which plays an important role in fabrication of $\mathrm{ZnO}$ structure (Movahedi et al., 2008). SEM images of $\mathrm{ZnO}$ nanostructure synthesized by task specific dicationic dibasic ionic liquid, [mmpim $]_{2}[\mathrm{OH}]_{2}$ is shown in fig. 12.
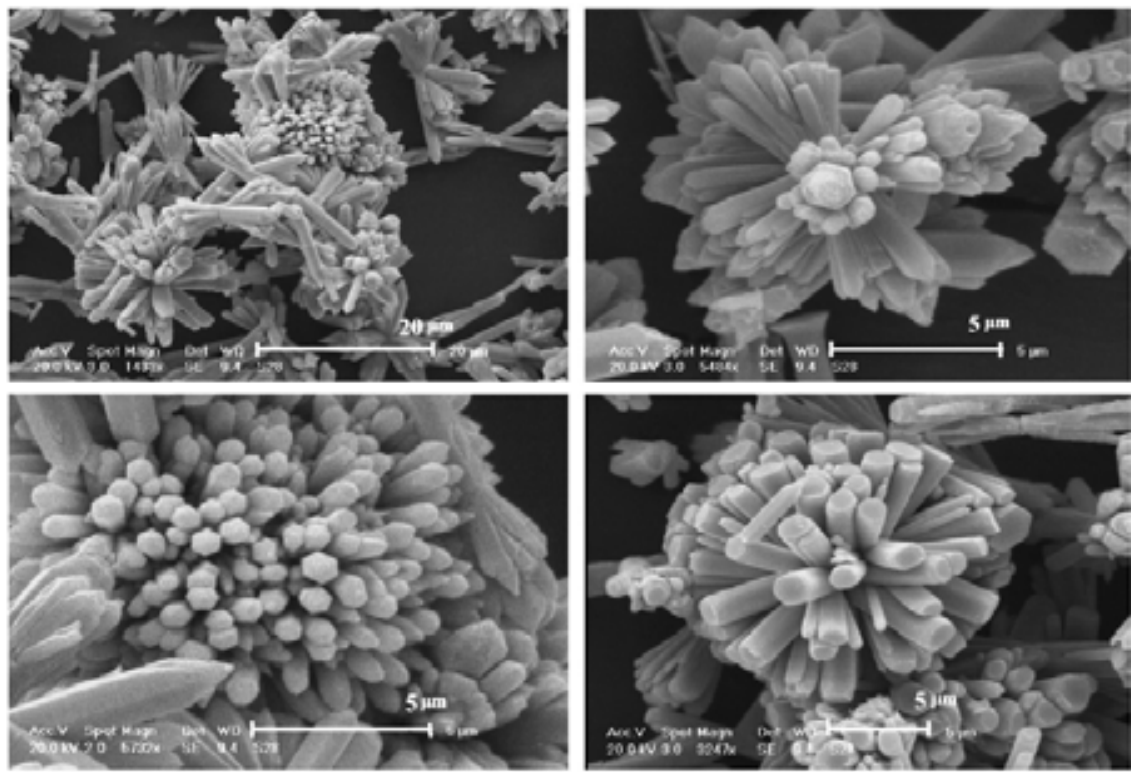

Fig. 12. SEM images of $\mathrm{ZnO}$ nanostructure synthesized by task specific dicationic dibasic ionic liquid, [mmpim $]_{2}[\mathrm{OH}]_{2}$, (Reproduced from Movahedi et al. (2008) Materials Letters 62 3856-3858, Copyright (2008), with permeation from Elsevier)

The $\mathrm{a}-\mathrm{Fe}_{2} \mathrm{O}_{3}$ with various morphologies has been synthesized via an ionic liquid assisted hydrothermal synthetic method by Lian and coworkers (Lian et al. 2009) The results indicate that the as-prepared samples are $\alpha-\mathrm{Fe}_{2} \mathrm{O}_{3}$ nanoparticles, mesoporous hollow microspheres, 
microcubes, and porous nanorods. The UV-vis measurements suggest that the assynthesized pure $\mathrm{a}-\mathrm{Fe}_{2} \mathrm{O}_{3}$ with various morphologies possess different optical properties depending on the shape and size of the samples. The magnetic hysteresis measurements indicate the interesting magnetic property evolution in the as-prepared $\mathrm{a}-\mathrm{Fe}_{2} \mathrm{O}_{3}$ samples, which is attributed to the superstructure or the shape anisotropy of the samples.

\subsection{Microwave heating synthesis}

The application of microwave heating in synthetic chemistry is a fast-growing research area due to its advantages such as rapid volumetric heating, higher reaction rate, and selectivity, reducing reaction time often by orders of magnitude and increasing yields of products compared with conventional heating methods. As a result, this has opened up the possibility of realizing fast synthesis of materials in a short time. From the perspective of microwave chemistry, one of the key important advantages of room temperature ionic liquids is the presence of large organic positive ions with a high polarizability. Therefore, room temperature ionic liquids are good media for absorbing microwaves, leading to a high heating rate. Lately, by combining the advantages of both room temperature ionic liquids and microwave heating, a new microwave-assisted ionic liquid method has developed for fast controlled synthesis of nanorods and nanowires of Te and $\mathrm{ZnO}$ (Jiang \& Zhu, 2005). Zhu and coworkers (Zhu et al. 2004) synthesized single-crystal tellurium nanowires using microwave heating in n-butylpyridinium tetrafluoroborate ionic liquid in the presence of polymer surfactant of poly(vinylpyrrolidone) (PVP). Li and coworkers ( $\mathrm{Li}$ et al. 2005) synthesized large-size single-crystal gold nanosheets by microwave heating of $\mathrm{HAuCl}_{4}$ in [BMIM] $\left[\mathrm{BF}_{4}\right]$, without any additional template agent. Subsequently, $\mathrm{PbCrO}_{4}$ rods or bundlelike $\mathrm{Pb}_{2} \mathrm{CrO}_{5}, \mathrm{Bi}_{2} \mathrm{Se}_{3}$ nanosheets, sulfide $\mathrm{M}_{2} \mathrm{~S}_{3}$ nanorods, single-crystalline cryptomelane-type manganese oxide octahedral molecular sieve (OMS-2) nanoneedles, and nanorods, metal fluorides such as $\mathrm{FeF}_{2}, \mathrm{CoF}_{2}, \mathrm{ZnF}_{2}, \mathrm{LaF}_{3}, \mathrm{YF}_{3}, \mathrm{SrF}_{2}$, metal-oxide like $\mathrm{Fe}_{2} \mathrm{O}_{3}$, carbon-coated core shell structured copper or nickel nanoparticles and CNTs/Pt or CNTs/Rh composites have successfully been fabricated by microwave-assisted synthesis method in ionic liquids (Wang \& Zhu, 2005, Jiang et al., 2006, Singh et al., 2008, Liu et al., 2006).

Single-crystalline $\mathrm{Bi}_{2} \mathrm{~S}_{3}$ and $\mathrm{Sb}_{2} \mathrm{~S}_{3}$ nanorods have been synthesized using the microwaveassisted ionic liquid method by Jiang and Zhu (Jiang \& Zhu, 2005). The starting reagents were $\mathrm{Bi}_{2} \mathrm{O}_{3}$ or $\mathrm{Sb}_{2} \mathrm{O}_{3}, \mathrm{HCl}, \mathrm{Na}_{2} \mathrm{~S}_{2} \mathrm{O}_{3}$, and ethylene glycol (EG) or ethanolamine, and the ionic liquid used was 1-butyl-3-methylimidazolium tetrafluoroborate ([BMIM][BF 4$]$ ). These experiments showed that the ionic liquid played an important role in the morphology of $\mathrm{M}_{2} \mathrm{~S}_{3}(\mathrm{M}) \mathrm{Bi}, \mathrm{Sb}$ ). Single-crystalline $\mathrm{Bi}_{2} \mathrm{~S}_{3}$ nanorods could be prepared in the presence of [BMIM] $\left[\mathrm{BF}_{4}\right]$. However, urchinlike $\mathrm{Bi}_{2} \mathrm{~S}_{3}$ structures consisting of nanorods were formed without using [BMIM] $\left[\mathrm{BF}_{4}\right]$. Single-crystalline $\mathrm{Sb}_{2} \mathrm{~S}_{3}$ nanorods were obtained in the presence of $[\mathrm{BMIM}]\left[\mathrm{BF}_{4}\right]$. However, single-crystalline $\mathrm{Sb}_{2} \mathrm{~S}_{3}$ nanosheets could be prepared in the absence of $[\mathrm{BMIM}]\left[\mathrm{BF}_{4}\right]$.

The morphologies of the samples were investigated by transmission electron microscopy (TEM). Figure 13a,b shows TEM micrographs of sample $1\left(\mathrm{Bi}_{2} \mathrm{~S}_{3}\right)$ synthesized under microwave heating at $190{ }^{\circ} \mathrm{C}$ for $10 \mathrm{~min}$ without using the ionic liquid [BMIM] [BF 4 , from which one can see the urchinlike morphology of $\mathrm{Bi}_{2} \mathrm{~S}_{3}$.

\subsection{Emulsions or microemulsions synthesis}

Reverse microemulsions are mostly transparent, isotropic and thermodynamically stable liquid media with nanosized water droplets dispersing in a continuous oil phase and 
stabilized by an adsorbed surfactant film at the liquid-liquid interface (Chokshi et al., 1989). One of the important applications of microemulsions involves the preparation of nanoparticles, nanowires, and nanorods (Qi et al., 1997). More recently, some investigations demonstrated that ionic liquids could substitute water or oil to form novel microemulsions in the presence of surfactant

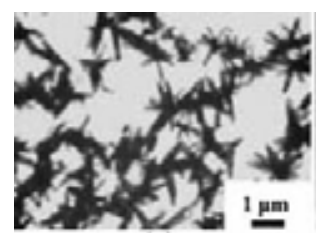

(a)

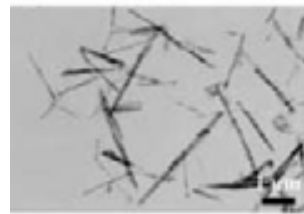

(d)

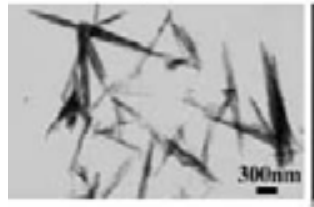

(g)

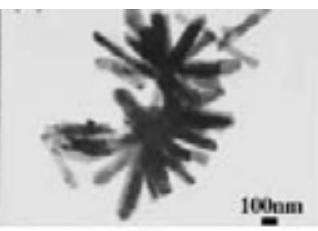

(b)

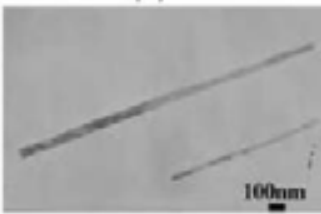

(e)

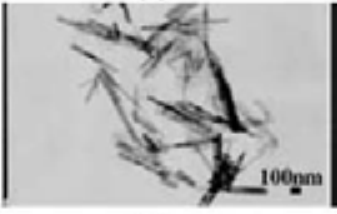

(h)

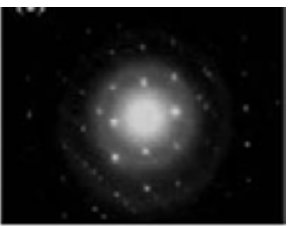

(c)

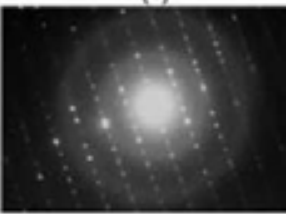

(f)

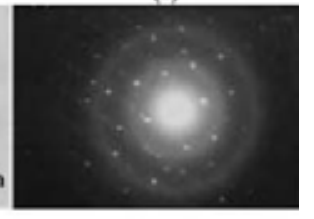

(i)

Fig. 13. TEM micrographs of three typical $\mathrm{Bi}_{2} \mathrm{~S}_{3}$ samples: (a and b) sample 1 ; (d and e) sample 2 synthesized via microwave-assisted ionic liquid method at $190{ }^{\circ} \mathrm{C}$ for $10 \mathrm{~min}$; (g and h) sample 3 synthesized via microwave-assisted ionic liquid method at $190^{\circ} \mathrm{C}$ for $30 \mathrm{~s}$. (c, f, and i) Electron diffraction patterns of individual nanorods from samples 1, 2, and 3, respectively. (Reproduced from Jiang \& Zhu (2005) J. Phys. Chem. B, 109, 4361-4364, Copyright (2005), with permeation from American Chemical Society)

Ionic liquid microemulsions have both the advantages of ionic liquids and microemulsion, which can overcome the inability of ionic liquids to dissolve a number of chemicals including some hydrophilic substances and then broaden the utilization of ionic liquids. Some papers reported that ionic liquid could substitute water to form nonaqueous ionic liquid microemulsion and exist as nanosized polar domains dispersed in cyclohexane with the aid of surfactant ( $\mathrm{Li}$ et al., 2007). Gao, et al. prepared and characterized TX-100/ $\mathrm{H}_{2} \mathrm{O} / 1$ butyl-3-methylimidazolium hexafluorophosphate $\left(\mathrm{bmimPF}_{6}\right)$ microemulsion using different techniques. Their research results showed that water domains existed in the water-inbmimPF 6 microemulsion, which could dissolve salts (Gao et al., 2005).

\subsection{Electrodeposition synthesis}

Electrochemical deposition is an economical and convenient choice for preparing uniform and size controllable nano-materials. It is meaningful to combine the advantages of aqueous ionic liquid microemulsions and the electrodeposition method for preparing materials. 
Aqueous ionic liquid microemulsions as electrolytes for electrochemical deposition are special and different from traditional aqueous solution and ionic liquids. Electrochemical approaches have been among the first to be used for the fabrication of inorganic nanoparticles and nanostructured films in ionic liquids. The properties of ionic liquids opened the door to the electrodeposition of metals and semiconductors at room temperature, which was previously only possible from high-temperature molten salts. For example, $\mathrm{Al}, \mathrm{Mg}, \mathrm{Ti}, \mathrm{Si}, \mathrm{Ge}$ and rare-earth-elements related materials can be obtained from ionic liquids.

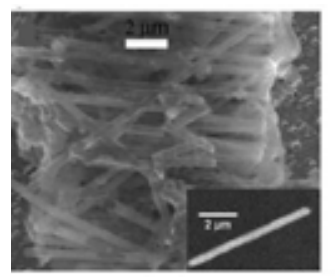

(a)

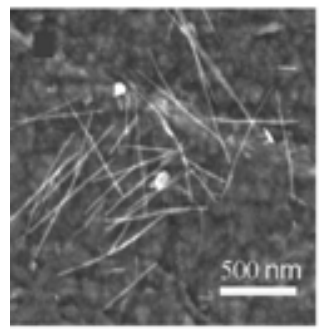

(c)

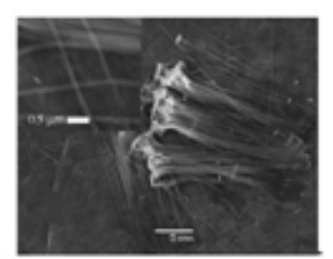

(b)

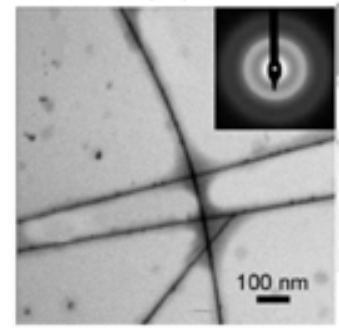

(d)

Fig. 14. SEM images of the Si NWs prepared with membranes with nominal pore diameter of $400 \mathrm{~nm}$ and a thickness of $12 \mu \mathrm{m}$ (a), $110 \mathrm{~nm}$ and $20 \mu \mathrm{m}$ (b), and 15 and $800 \mathrm{~nm}$ (c) after partial or total dissolution of the PC membranes. The inset of the image in panel a exhibits an isolated $400 \mathrm{~nm}$ NW after a supplementary washing procedure to show its smooth surface after total dissolution of the membrane. The inset of the image in panel b shows some isolated $110 \mathrm{~nm}$ NWs with a good uniformity for the diameters and regular and smooth edges. (d) A TEM picture of isolated $15 \mathrm{~nm}$ NWs with the corresponding electron diffraction pattern (Reproduced from Mallet et al (2008) Nano Letter 2008 8, 10, 3468-3474 Copyright (2008), with permeation from American Chemical Society)

Silicon nanowires were fabricated for the first time by electrochemical template synthesis at room temperature by J. Mallet and coworkers (Mallet et al. 2008). This innovative, cheap, and simple process consists of electroreduction of $\mathrm{Si}$ ions using a nonaqueous solvent and insulating nanoporous membranes with average pore diameters from 400 to $15 \mathrm{~nm}$ which fix the nanowires diameters

Characterization techniques such as scanning and transmission electron microscopies, infrared absorption measurements, X-ray diffraction experiments, energy dispersive X-ray, and Raman spectrometries show that the as-deposited silicon nanowires are amorphous, composed of pure Si and homogeneous in sizes with average diameters and lengths well matching with the nanopores' diameters and the thicknesses of the membranes. Thanks to 
annealing treatments, it is possible to crystallize the Si nanowires, demonstrating the potentiality for this innovative electrochemical process to obtain a wide range of $\mathrm{Si}$ nanowires with well controlled diameters and lengths. Figure 14 panels a-c are SEM images of nanowires prepared in PC membrane with pore diameters of 400, 110, and $15 \mathrm{~nm}$, respectively, and thicknesses of $12 \mu \mathrm{m}, 20 \mu \mathrm{m}$, and $800 \mathrm{~nm}$, respectively, after partial or total dissolution of the membranes and collection on a HOPG substrate. Figure $14 \mathrm{~d}$ is a TEM image of $15 \mathrm{~nm}$ NWs deposited on a Ni grid.

Ultrafine monodisperse gold nanoparticles (AuNPs) were synthesized by an elegant sputtering of gold onto 1-nbutyl- 3-methylimidazolium hexafluorophosphate (BMI-PF 6 ) ionic liquid by Khatri and coworkers (Khatri et al. 2008). It was found that the BMI-PF 6 supramolecular aggregates were loosely coordinated to the gold nanoparticles and were

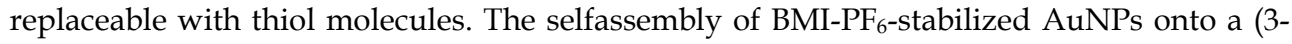
mercaptopropyl)trimethoxysilane (MPS)-functionalized silicon surface in 2D arrays, followed by dodecanethiol (DDT) treatment, have been demonstrated using X-ray photoelectron spectroscopy, field emission scanning electron microscopy, and contact angle measurements. DDT treatment of tethered

AuNPs revealed two types of interactions between AuNPs and the MPS-functionalized surface: (a) AuNPs anchor through Au-S chemisorption linkage resulting in strong immobilization and (b) some of the AuNPs are supported by physisorption, driven by BMIPF6. The attachment of these particles remains unchanged with sonication. The replacement of $\mathrm{BMI}_{-\mathrm{PF}_{6}}$ aggregates from physisorbed AuNPs with dodecanethiol molecules advances the dilution of their interaction with the MPS-functionalized surface, and they subsequently detach from the silicon surface. The present finding is promising for the immobilization of ionic liquid-stabilized nanoparticles, which is very desirable for electronic and catalytic device fabrication. Additionally, these environmentally friendly AuNPs are expected to replace conventional citrate-stabilized AuNPs.

\subsection{Nanocasting technique and ionic liquid}

A nanocasting technique (Attard et al., 1995, Polarz \& Antonietti, 2002) was employed for the synthesis of several mesoporous $\mathrm{SiO}_{2}$ materials. Zhou and Antonietti used $\left[\mathrm{C}_{16} \mathrm{Mim}\right][\mathrm{Cl}]$ as the template to prepare monolithic super-microporous $\mathrm{SiO}_{2}$ (pore diameter $1.3 \mathrm{~nm}$, wall thickness $1.4 \mathrm{~nm}$, surface area $1340 \mathrm{~m}^{2} \mathrm{~g}_{-}{ }^{1}$ ) with lamellar order via a nanocasting technique. (Zhou \& Antonietti, 2003) They further reported a systematic investigation employing $\left[\mathrm{C}_{10} \mathrm{Mim}\right][\mathrm{Cl}]\left(\left[\mathrm{C}_{10} \mathrm{Mim}\right]{ }^{+}=\right.$decyl-3-methylimidazolium $),\left[\mathrm{C}_{14} \mathrm{Mim}\right][\mathrm{Cl}],\left[\mathrm{C}_{16} \mathrm{Mim}\right][\mathrm{Cl}]$, and $\left[\mathrm{C}_{18} \mathrm{Mim}\right][\mathrm{Cl}]\left(\left[\mathrm{C}_{18} \mathrm{Mim}\right]^{+}=\right.$1-octadecyl-3-methylimidazolium) as templates, and again obtained lamellar $\mathrm{SiO}_{2}$ with pore diameters in the range of 1.2-1.5 nm. (Zhou \& Antonietti, 2004) In addition, mesoporous $\mathrm{SiO}_{2}$ with wormlike pores (pore diameter $2.5 \mathrm{~nm}$, wall thickness 2.5-3.1 nm, surface area $801 \mathrm{~m}^{2} \mathrm{~g}_{-}{ }^{1}$ ) was synthesized using [BMim] $\left[\mathrm{BF}_{4}\right.$ ] as the template. (Zhou \& Schattka, 2004) The authors proposed a hydrogen bond-co- $\Pi-\Pi$ stacking mechanism, in which the hydrogen bonds formed between $\left[\mathrm{BF}_{4}\right]^{-}$and the $\mathrm{SiO}_{2}$ matrix together with the $\Pi-\Pi$ stacking interaction of the neighboring imidazolium rings led to the mutual packing and formation of mesoporous $\mathrm{SiO}_{2}$ (Fig. 16).

The synthesis of mesoporous $\mathrm{SiO}_{2}$ using ionic liquids as new templates has furnished new examples in the synthesis of mesoporous materials. However, the efforts made in this regard are still minor, compared to the huge efforts made in the synthesis of mesoporous materials using other templates. The advantages of using ionic liquids instead of conventional solvents are not obvious, the synthesis mechanisms in different cases are not quite clear, and 


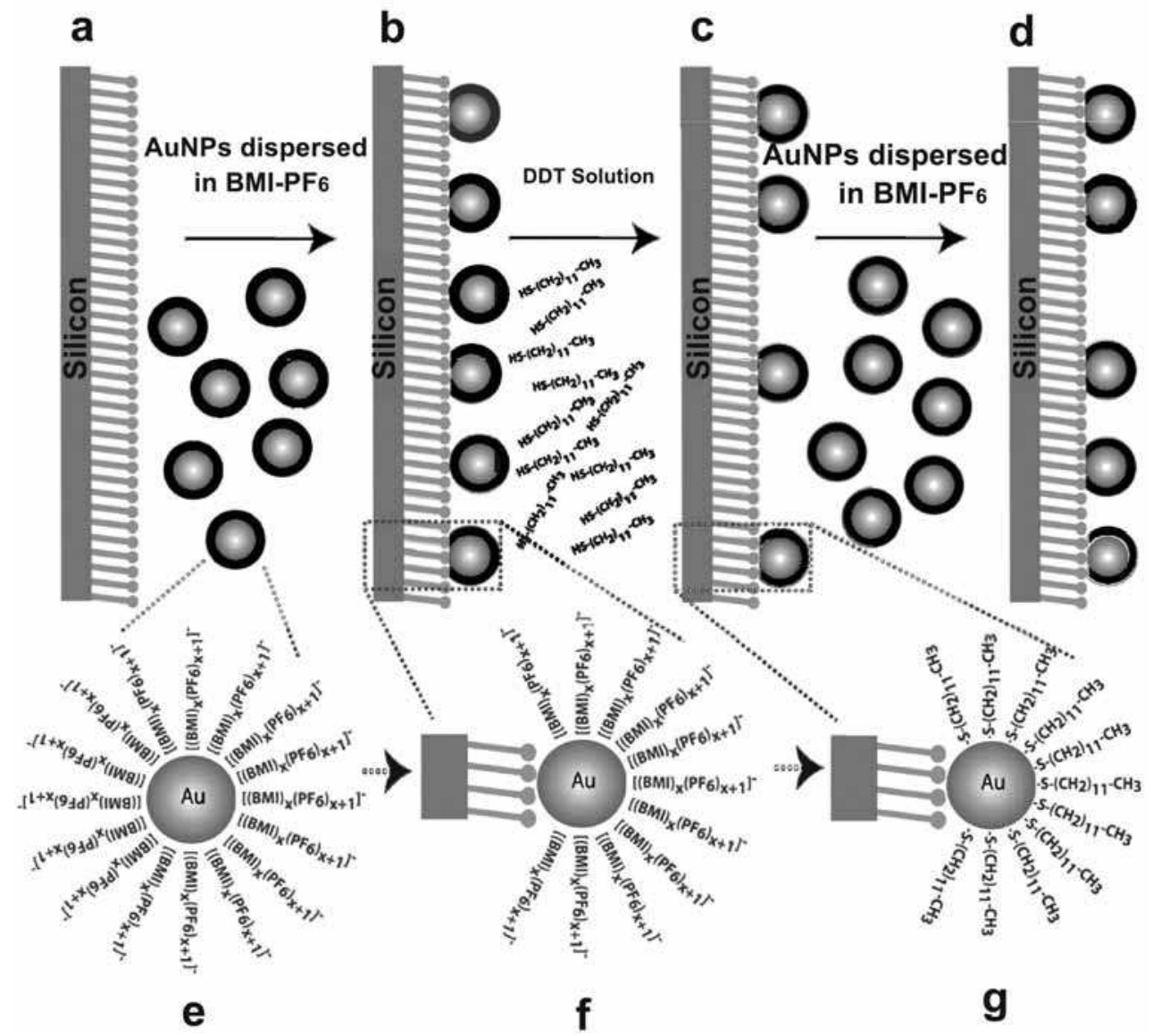

Fig. 15. Simple Model to Illustrate the Interaction of BMI-PF 6 -Stabilized AuNPs on the MPSFunctionalized Surface (Reproduced from Khatri et al. (2008) Langmuir 24, 7785-7792, Copyright (2008), with permeation from American Chemical Society)

${ }^{a}$ Illustration of (a) an MPS monolayer on a silicon surface and (b) the immobilization of BMI-PF $6^{-}$ stabilized AuNPs on the mercapto-functionalized silicon surface followed by (c) dodecanethiol treatment, which replaces the protective coating of $\mathrm{BMI}_{-} \mathrm{PF}_{6}$ supramolecular aggregates and detaches the physisorbed AuNPs from the silicon surface. (d) Immobilization of new AuNPs. These particles are probably tethered to vacant sites created by the detachment of physisorbed AnNPs. (e). BMI-PF6stabilized ultrafine gold nanoparticles in the dispersed phase. (f). Interaction of BMI-PF 6 -stabilized AuNPs with a mercapto-functionalized surface. The strong affinity between gold and the mercapto group replaces the BMI-PF 6 aggregates from the localized area and results in Au-S chem isorption bonding. (g). Replacement of the BMI-PF6 protective layer by dodecanethiol molecules. 


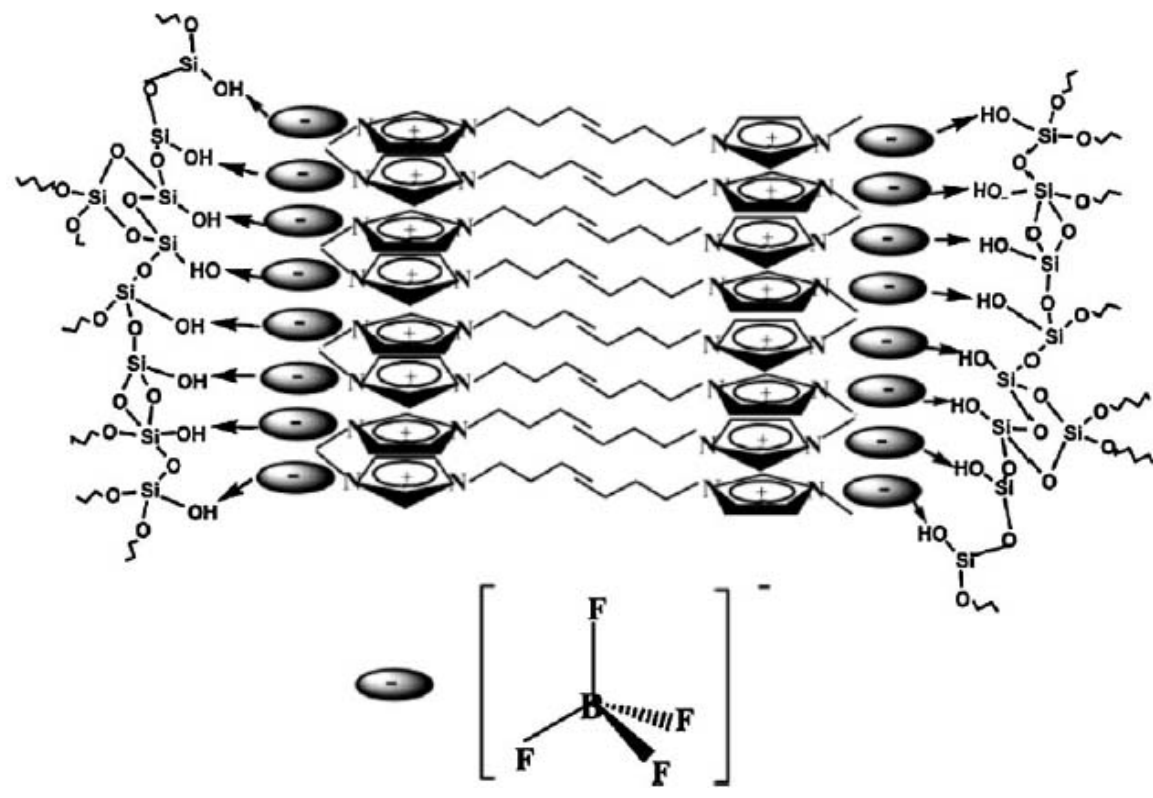

Fig. 16. A ח-ח stacking model proposed to explain the formation of mesoporous $\mathrm{SiO}_{2}$ using [BMim] $\left[\mathrm{BF}_{4}\right]$ as the template. In this model, $\left[\mathrm{BF}_{4}\right]$ anions interact with the silanol groups and arrange along the pore walls, and [BMim] cations are aligned accordingly, forming $\Pi-\Pi$ stacking interactions between the aromatic motifs. (Reproduced from Zhou et al. (2004) Nano Lett. 4, 477, Copyright 2004,with permission of the American Chemical Society)

the knowledge regarding the morphological control of mesoporous $\mathrm{SiO} 2$ is still limited. It is not clear how the use of different ionic liquids may lead to different morphologies and how synthesis conditions may influence the morphology. Regardless of these limitations, this idea has opened up new avenues for the synthesis of hierarchical porous materials and periodic mesoporous organosilicas.

\section{Conclusion}

The updated application of the ionic liquid in the synthesis of inorganic nanomaterials was briefly outlined. The main emphasis of the outline was a focus on the preorganized structure of the ionic liquid as template effect for inorganic nanomaterials. The particular strength of ionic liquids is their virtually unlimited flexibility of anions and cations combinations. As the cation or anion in the ionic liquid can be tailored by functional substitutes, the size and size distribution of the ionic liquid-stabilized metal nanoparticles can be easily controlled too. In case ionic liquid phase behavior, chemical composition, and reactivity are also considered, ionic liquids provide a flexible toolbox for the fabrication of inorganics with various (and variable) properties simply by designing the appropriate precursor. These precursors are entities which are defined molecularly, which can be well characterized and studied as the transformation to the inorganic proceeds. 
Although the application of the ionic liquid in inorganic nanomaterials is still in its early days, many claim that the field of ionic liquid is becoming a promising area of research in the nanomaterials in the years to come.

\section{Acknowlegment}

The author wishes to express her gratitude to National Elite Foundation for the financial support.

\section{References}

Abedin, S. Z. El.; Borissenko, N. \& Endres, F. (2004). Electrodeposition of nanoscale silicon in a room temperature ionic liquid. Electrochem. Commun. 6, 5, 510-514. 13882481

Antonietti, M.; Kuang, D. B.; Smarsly, B. \& Zhou, Y. (2004). Ionic liquids for the convenient synthesis of functional nanoparticles and other inorganic nanostructures. Angew. Chem. Int. Ed, 43, 38 , 4988-4992, 1521-3773

Attard, G.S.; Glyde,J. C. \& Goltner, C. G. (1995). Liquid-crystalline phases as templates for the synthesis of mesoporous silica. Nature, 378,6555, 366-368, 0028-0836

Binnemans, K. (2005). Ionic Liquid Crystals. Chem. Rev. 105, 11, 4148-4204, 0009-2665

Bühler,G. \& Feldmann,C. (2006). Microwave-assisted synthesis of luminescent $\mathrm{LaPO}_{4}$ : Ce,Tb nanocrystals in ionic liquids. Angew. Chem. Int. Ed. 45, 29, 4864-4867, 1521-3773

Chokshi, K.; Qutubuddin, S. \& Hussam, A. (1989). Electrochemical investigation of microemulsions. J. Colloid Interf. Sci, 129, 2,315-326, 0021-9797

Cooper, E. R.; Andrews, C. D.; Wheatley, P. S.; Webb, P. B.; Wormald, P. \& Morris, R. E. (2004). Ionic liquids and eutectic mixtures as solvent and template in synthesis of zeolite analogues. Nature 430, 7003,1012-1016, 0028-0836

Dai, S.; Ju, Y. H.; Gao, H. J.; Lin, J. S.; Pennycook, S. J. \& Barnesc, C. E. (2000). Preparation of silica aerogel using ionic liquids as solvents. Chem Commun, 3, 243-244, 1359-7345

Dhasn, N. A.; Zaban, A. \& Gedanken, A. (1999). Article surface synthesis of Zinc Sulfide nanoparticles on silica microspheres: Sonochemical preparation, characterization, and optical properties. Chem. Mater. 11, 3, 806-813, 0897-4756

Ding, K. L. ; Miao, Z. J. ; Liu, Z. J.; Zhang, Z. F., Han, B. X., An, G. M.; Miao,S. D. \& Xie,Y. (2007) Facile synthesis of high quality $\mathrm{TiO}_{2}$ nanocrystals in ionic liquid via a microwave-assisted process. J. Am. Chem. Soc. 129, 20, 6362-6363, 0002-7863

Dobbs, W.; Suisse, J.-M.; Douce, L. \& Welter, R. (2006). Electrodeposition of silver particles and gold nanoparticles from ionic liquid-crystal precursors. Angew. Chem., Int. Ed. $45,25,4179-4182,1521-3773$

Dupont, J.; Fonseca, G. S.; Umpierre,A. P.; Fichtner, P. F. P. \& Teixeira, S. R. (2002). Transition-metal nanoparticles in imidazolium ionic liquids: Recycable catalysts for biphasic hydrogenation reactions. J. Am. Chem. Soc., 124, 16, 4228-4229, 0002-7863

Endres, F.; Bukowski, M.; Hempelmann, R. \& Natter, H.(2003). Electrodeposition of nanocrystalline metals and alloys from ionic liquids, Angew. Chem., Int. Ed, 42,29, 3428-3430, 1521-3773 
Flannigan, J. D.; Hopkins, D. S. D. \& Suslick, K. S. (2005). Sonochemistry and sonoluminescence in ionic liquids, molten salts, and concentrated electrolyte solutions. J Organomet Chem, 690, 15, 3513-3517, 0022-328X

Foneca, G. S.; Umpierre, A. P.; Fichtner, P. F.; Teixeira, S. R\&. Dupont, J. (2003). The use of imidazolium ionic liquids for the formation and stabilization of $\operatorname{Ir}^{0}$ and $\mathrm{Rh}^{0}$ nanoparticles: efficient catalysts for the hydrogenation of arenes. Chem. Eur. J. 9, 14, 3263-3269, 1521-3765

Fujimaki, M.; Ohki, Y. \& Nishikawa, H. (1997) Energy states of Ge-doped SiO2 glass estimated through absorption and photoluminescence. J. Appl. Phys., 81, 3 10421046, 0021-8979

Gao, Y. N.; Han, S. B.; Han, B. X.; Li, G. Z.; Shen, D. \& Li, Z. G. (2005) TX-100/Water/1Butyl-3-methylimidazolium hexafluorophosphate microemulsions. Langmuir, 21, 13, 5681-5684, 0743-7463

Green,W. H.; Le, K. P.; Grey, J.; Au, T. T. \& Sailor, M. J. (1997). White phosphors from a silicate-carboxylate sol-gel precursor that lack metal activator ions. Science, 276, 5320, 1826-1828, 0036-8075

Hao, Y.; Meng, G.; Ye,C.; Zhang, X. \& Zhang, L. (2005). Kinetics-Driven Growth of Orthogonally Branched Single-Crystalline Magnesium Oxide Nanostructures. J. Phys. Chem. B., 109, 22, 11204-11208, 1520-6106

Hayakawa, T.; Hiramitsu, A. \& Nogami, M.(2003) White light emission from radical carbonyl-terminations in $\mathrm{Al}_{2} \mathrm{O}_{3}-\mathrm{SiO}_{2}$ porous glasses with high luminescence quantum efficiencies. Appl. Phys. Lett., 82,18, 2975-2977, 0003-6951

Huang, J.; Jiang, T.; Han, B. X.; Gao, H. X.; Chang, Y. H.; Zhao, G. Y. \& Wu, W. Z. (2003). Hydrogenation of olefins using ligand-stabilized palladium nanoparticles in an ionic liquid. Chem. Commun. 14, 1654-1655, 1359-7345

Jiang, J.; Yu, S. H. ; Yao, W. T.; Ge, H. \& Zhang, G. Z. (2005) Morphogenesis and crystallization of Bi2S3 nanostructures by an ionic liquid-assisted templating route: synthesis, formation mechanism, and properties. Chem. Mater. 17, 24, 6094-6100, 0897-4756

Jiang, Y. \& Zhu, Y. J. (2005) Microwave-assisted synthesis of sulfide $\mathrm{M}_{2} \mathrm{~S}_{3}(\mathrm{M}=\mathrm{Bi}, \mathrm{Sb})$ nanorods using an ionic liquid J. Phys. Chem. B 109, 10, 4361-4364, 1520-6106

Jiang, J.; Yu, S. H; Yao, W. T.; Ge, H. \& Zhang, G. H. (2005). Morphogenesis and crystallization of $\mathrm{Bi}_{2} \mathrm{~S}_{3}$ nanostructures by an ionic liquid- assisted templating route: synthesis, formation mechanism, and properties. Chem. Mater., 17, 24, 60946100

Jiang, Y.; Zhu, Y. J.; Cheng, G. F. (2006) Synthesis of $\mathrm{Bi}_{2} \mathrm{Se}_{3}$ nanosheets by microwave heating using an ionic liquid. Cryst Growth Des, 6, 9, 2174-2176, 1528-7483

Jia, X.; Fan, H.; Zhang, F. \& Qin, L. (2010). Using sonochemistry for the fabrication of hollow ZnO microspheres. Ultrasonics Sonochemistry, 17, 2, 284-287, 1350-4177

Kaper, H.; Endres, F.; Djerdj, I., Antonietti, M.; Smarsly, B. M.; Maier, J. \& Hu, Y. S. (2007) Direct low-temperature synthesis of rutile nanostructures in ionic liquids. Small, 3, 10,1753-1763, 1613-6829

Khatri, O. P.; Adachi, K.; Murase, K.; Okazaki, K., Tsukasa Torimoto,T.; Tanaka,N.; Kuwabata, S. \& Sugimura, H.(2008). Self-assembly of ionic liquid (BMI-PF $)^{-}$ 
stabilized gold nanoparticles on a silicon surface: chemical and structural aspects. Langmuir, 24, 15, 7785-7792, 0743-7463

Kim, K. S.; Choi, S.; Cha, J. H.; Yeon, S. H. \& Lee, H. (2006). Facile one-pot synthesis of gold nanoparticles using alcohol ionic liquids. J. Mater. Chem. 16, 14, 1315-1317, 09599428

Kowsari, E. \& Faraghi, G. (2010) Ultrasound and ionic-liquid-assisted synthesis and characterization of polyaniline $/ \mathrm{Y}_{2} \mathrm{O}_{3}$ nanocomposite with controlled conductivity. Ultrasonics Sonochemistry, 17, 4, 718-725, 1350-4177

Kowsari, E. \& Faraghi, G. (2010). Synthesis by an ionic liquid-assisted method and optical properties of nanoflower $\mathrm{Y}_{2} \mathrm{O}_{3}$. Materials reserch Bull, 45, 8, 939-945, 0025-5408

Lee, C. K.; Vasam, C. S.; Huang, T. W.; Wang, H. M. J.; Yang, R. Y.; Lee, C. S. \& Lin, I. J. B. (2006). Silver(I) N-heterocyclic carbenes with long N-alkyl chains. Organometallics $25,15,3768-3775,0276-7333$

Lyu, S. C.; Zhang, Y; Ruh, H.; Lee, H. G.; Shim, H. W.; Suhc, E. K. \& Lee, C. J. (2002) Low temperature growth and photoluminescence of well-aligned zinc oxide nanowires. Chem. Phys. Lett, . 363, 1-2, 134-138, 0009-2614

Lee,Y. C.; Liu, Y. L.; Shen, J. L.; Hsu, I. J.; Cheng, P. W.; Cheng, C.F. \& Ko, C. H. (2004). Bluegreen luminescence from mesoporous MCM-48 molecular sieves. J.Non-Cryst. Solids , 341, 1-3, 16-20, 0022-3093

Li, W. J.; Shi, E. W.; Zhong, W. Z. \& Yin, Z. W. (1999) Growth mechanism and growth habit of oxide crystals. J Cryst Growth, 203, 1-2, 186-196, 0022-0248

Li, Z.; Liu, Z.; Zhang, J.; Han, B.; Du, J.; Gao, Y., Jiang, T (2005). Synthesis of Single-Crystal Gold Nanosheets of Large Size in Ionic Liquids. J Phys Chem B,109,30, 14445-1448, 1520-6106

Lian, J; Duan, X.; Ma, J; Peng, P.; Kim, T. \& Zheng, W. (2009). Hematite ( $\left(\mathrm{a}-\mathrm{Fe}_{2} \mathrm{O}_{3}\right)$ with various morphologies: ionic liquid-assisted synthesis, formation mechanism, and properties, ACSNano, 3 , 11, - 3749-3761, 1936-0851

Liu, X.; Peng,P.; Ma, J.; Zheng, W. (2009) Preparation of novel CdSe microstructure by modified hydrothermal method, Mater lett, 63,8, 673-675, 0167-577X

Luo, H.; Xu, C; Zou, D.; Wang, L.; Ying, T. (2008). Hydrothermal synthesis of hollow $\mathrm{MoS}_{2}$ microspheres in ionic liquids/water binary emulsions. Mater lett, 62,20 3558-3560, 0167-577X

Li, N; Gao, Y. A.; Zheng, L. Q.; Zhang, J.; Yu, L. \& Li, X. W. (2007). Studies on the micropolarities of bmimBF 4 TX-100/toluene ionic liquid microemulsions and their behaviors characterized by UV-Visible spectroscopy. Langmuir 23, 3, 1091-1097, 0743-7463

Liu, Z.; Sun, Z.; Han, B., Zhang, J.; Huang, J.; Du, J. \& Miao, S. (2006) Microwave-Assisted Synthesis of $\mathrm{Pt}$ Nanocrystals and Deposition on Carbon Nanotubes in Ionic Liquids. J Nanosci Nanotech, 2006, 6,1,175-179, 1550-7033

Movahedi, M.; Kowsari, E.; Mahjoub, A. R.; Yavari, I. (2008) A task specific basic ionic liquid for synthesis of flower-like $\mathrm{ZnO}$ by hydrothermal method. Mater lett, 62, 23, 3856$3858,0167-577 X$ 
Mallet et al (2008) Growth of Silicon Nanowires of Controlled Diameters by Electrodeposition in Ionic Liquid at Room Temperature. Nano Lett, 8, 10, 3468-3474, 1530-6984

Mu, X.; Evans, D. G. \& Kou,Y. (2004) A general method for preparation of PVP-stabilized noble metal nanoparticles in room temperature ionic liquids. Catal. Lett. 97, 3-4, 151-154, 1011-372X

Nakashima, T. \& Kimizuka, N. (2003) Interfacial synthesis of hollow $\mathrm{TiO}_{2}$ microspheres in ionic liquids. J. Am. Chem. Soc., 125, 21 6386-6387, 0002-7863

Parnham, E. R.; Wheatley, P. S.; Morris, R. E. (2006) The ionothermal synthesis of SIZ-6-a layered aluminophosphate, Chem. Commun., 4, 380-382, 1359-7345

Zhang, M.; Xu, X.; Zhang, M. (2008). Hydrothermal synthesis of sheaf-like $\mathrm{CuO}$ via ionic liquids. Mater lett, 62, 3, 385-388, 0167-577X

Pifferi, A.; Taroni, P.; Torricelli, A.; Valentini, G.; Mutti, P.; Ghislotti, G. \& Zanghieri, L. (1997) Nanosecond time-resolved emission spectroscopy from silicon implanted and annealed $\mathrm{SiO}_{2}$ layers. Appl. Phys.Lett., 70, 3, 348-350, 0003-6951

Polarz, S. \& Antonietti, M. (2002). Porous materials via nanocasting procedures: innovative materials and learning about soft-matter organization. Chem. Commun. 22, 25932604, 1359-7345

Qi, L.; Ma, J.; Cheng, H.; Zhao, Z. (1997) Reverse micelle based formation of $\mathrm{BaCO}_{3}$ nanowires. J. Phys. Chem. B 101, 18, 3460-3463, 1520-6106

Ramı́rez, E. B.; Huanosta, A.; Sebastian, J. P.; Huerta, L.; Ortiz,A.;. Alonso,J. C. (2007). Structure, composition and electrical properties of YSZ films deposited by ultrasonic spray pyrolysis J. Mater. Sci,.. 42, 3, 901-907, 0022-2461

Scheeren, C. W.; Machado, G.; Dupont, J.; Fichtner, P. F. P. \& Texeira, S. R. (2003). Nanoscale $\mathrm{Pt}(0)$ particles prepared in imidazolium room temperature ionic liquids: Synthesis from an organometallic precursor, characterization, and catalytic properties in hydrogenation reactions. Inorg. Chem. 42, 15, 4738-4742, 0020-1669

Singh, P.; Katyal, A.; Kalra, R.; Chandra, R. (2008). Copper nanoparticles in an ionic liquid: an efficient catalyst for the synthesis of bis-(4-hydroxy-2-oxothiazolyl)methanes. Tetrahedron Lett, 49,4, 727-730, 0040-4039

Suslick, K. S. (1988) Ultrasound:, VCH, Weinhein, Germany.

Suslick, K. S.; Choe, S. B.; Cichowlas, A. A. \& Grinstaff, M. W. (1991). Sonochemical synthesis of amorphous iron. Nature , 353, 414-416, 0028-0836

Taubert, A. \& Li, Z. (2007). Inorganic materials from ionic liquids. Dalton Trans. 7, 723-727, $1477-9226$

Taubert, A. (2004) $\mathrm{CuCl}$ nanoplatelets from an ionic liquid-crystal precursor. Angew. Chem., Int. Ed. 43, 40, 5380-5382, 1433-7851

Taubert, A.; Palivan, C.; Casse, O.; Gozzo, F. \& Schmitt, B.(2007) Ionic liquid-crystal precursors (ILCPs) for $\mathrm{CuCl}$ platelets: The origin of the exothermic peak in the DSC curves. J. Phys. Chem. C, 111,11, 4077-4082, 1932-7447

Taubert, A.; Arbell, I.; Mecke, A. \& Graf, P. (2006). Photoreduction of a crystalline Au(III) complex: a solid-state approach to metallic nanostructures. Gold Bull. 39, 4, 205-211, 0017-1557 
Taubert, A.; Steiner, P. \& Mantion, A.(2005). Ionic liquid crystal precursors for ilnorganic particles: phase diagram and thermal properties of a $\mathrm{CuCl}$ nanoplatelet precursor. J. Phys. Chem. B 109, 32, 15542-15547, 1520-6106

Taubert, A. (2005) (Sub) Micron $\mathrm{CaF}_{2}$ cubes and hollow rods from ionic liquid emulsions. Acta Chim. SloV. 52, 2, 168-170, 1318-0207

Wang, S. L. \& Ong, C. K. (2002). Epitaxial Y-stabilized ZrO2 films on silicon: Dynamic growth process and interface structure. Appl. Phys. Lett,. 80, 14, 2541-2543, 00036951

Wang, W. W. \& Zhu, Y. J. (2005). Synthesis of $\mathrm{PbCrO}_{4}$ and $\mathrm{Pb}_{2} \mathrm{CrO}_{5}$ rods via a microwaveassisted ionic liquid method. Cryst Growth Des, 5, 2, 505-507, 1528-7483

Wang, Y. \& Yang, H. (2005) Synthesis of CoPt nanorods in ionic liquids. J. Am. Chem. Soc. $127,15,5316-5317,0002-7863$

Yavari, I.; Mahjoub, A. R.; Kowsari, E.; Movahedi, M. (2009). Synthesis of ZnO nanostructures with controlled morphology and size in ionic liquids. J. Nanopart. Res., 11, 4, 861-868, 1388-0764

Yoo, K.; Choi, H. \& Dionysiou, D. D. (2004). Ionic liquid assisted preparation of nanostructured $\mathrm{TiO}_{2}$ particles Chem. Commun.17, 2000-2001, 1359-7345

Zhu, H.; Huang, J.-F.; Pan, Z.; Dai, S. (2006). Ionothermal synthesis of hierarchical ZnO nanostructures from ionic-liquid precursors. Chem. Mater. 18, 18, 4473-4477, 0897 4756

Zhu,Y. Wang, W.; Qi, R. \& Hu, X. (2004) Microwave-assisted synthesis of single-crystalline tellurium nanorods and nanowires in ionic liquids. Angew. Chem., Int. Ed. 43,11, 1410-1414, 1521-3773

Zhou, Y. \& Antonietti, M. J. (2003). Synthesis of very small $\mathrm{TiO}_{2}$ nanocrystals in a roomtemperature ionic liquid and their self-assembly toward mesoporous spherical aggregates. J Am. Chem. Soc. 125, 49 14960-14961, 0002-7863

Zhu, Y. J.; Wang, W. W.; Qi, R. J. \& Hu, X. L. (2004). Microwave-Assisted Synthesis of SingleCrystalline Tellurium Nanorods and Nanowires in Ionic Liquids. Angew Chem Int Ed, 43,11, 1410-1414, 1521-3773

Zhou, Y.; Schattka, J. H. \& Antonietti, M. (2004). Room-temperature ionic liquids as template to monolithic mesoporous silica with wormlike pores via a sol-gel nanocasting technique. Nano Lett. 4,3, 477-481, 1530-6984

Zhou, Y. \& Antonietti, M. (2004). A Series of highly ordered, super-microporous, lamellar silicas prepared by nanocasting with ionic liquids. Chem. Mater, 16, 3, 544-550, 08974756

Zhou, Y. \& Antonietti, M. (2003). Preparation of highly ordered monolithic supermicroporous lamellar silica with a room-temperature ionic liquid as template via the nanocasting technique. Adv. Mater. 15, 17, 1452-1455, 1521-4095

Žilková, N.; Zukal, Z. \& Ćejka, J. (2006). Synthesis of organized mesoporous alumina templated with ionic liquids. Micropor. Mesopor. Mater. 95, 1-3, 176-179. 1387-1811

Zheng, Y.; Yu, X.; Xu, X.; Jin, D. \& Yue, L. (2010). Preparation of ZnO particle with novel nut-like morphology by ultrasonic pretreatment and its luminescence property. Ultrasonics Sonochemistry, 17, 1, 7-10, 1350-4177 
Zhou, Y. \& Antonietti, M. (2003). Synthesis of very small $\mathrm{TiO}_{2}$ nanocrystals in a roomtemperature ionic liquid and their self-assembly toward mesoporous spherical aggregates. J Am Chem Soc 125, 49, 14960-14961, 0002-7863

Zhu, H.; Huang, J.; Pan, Z. \& Dai, S. (2006). Ionothermal Synthesis of Hierarchical ZnO Nanostructures from Ionic-Liquid Precursors. Chem Mater, 18,18, 4473-4477, 08974756 


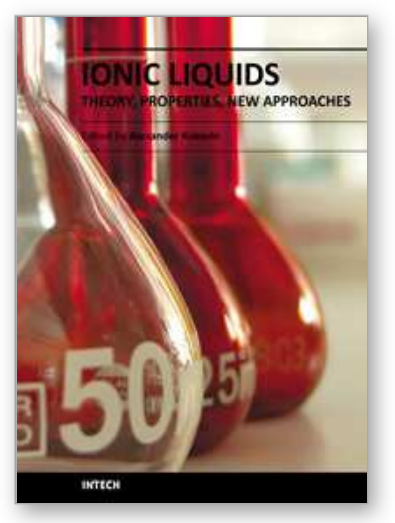

\section{Ionic Liquids: Theory, Properties, New Approaches}

Edited by Prof. Alexander Kokorin

ISBN 978-953-307-349-1

Hard cover, 738 pages

Publisher InTech

Published online 28, February, 2011

Published in print edition February, 2011

Ionic Liquids (ILs) are one of the most interesting and rapidly developing areas of modern physical chemistry, technologies and engineering. This book, consisting of 29 chapters gathered in 4 sections, reviews in detail and compiles information about some important physical-chemical properties of ILs and new practical approaches. This is the first book of a series of forthcoming publications on this field by this publisher. The first volume covers some aspects of synthesis, isolation, production, modification, the analysis methods and modeling to reveal the structures and properties of some room temperature ILs, as well as their new possible applications. The book will be of help to chemists, physicists, biologists, technologists and other experts in a variety of disciplines, both academic and industrial, as well as to students and PhD students. It may help to promote the progress in ILs development also.

\section{How to reference}

In order to correctly reference this scholarly work, feel free to copy and paste the following:

Elaheh Kowsari (2011). The Design of Nanoscale Inorganic Materials with Controlled Size and Morphology by Ionic Liquids, Ionic Liquids: Theory, Properties, New Approaches, Prof. Alexander Kokorin (Ed.), ISBN: 978953-307-349-1, InTech, Available from: http://www.intechopen.com/books/ionic-liquids-theory-properties-newapproaches/the-design-of-nanoscale-inorganic-materials-with-controlled-size-and-morphology-by-ionic-liquids

\section{INTECH}

open science | open minds

\author{
InTech Europe \\ University Campus STeP Ri \\ Slavka Krautzeka 83/A \\ 51000 Rijeka, Croatia \\ Phone: +385 (51) 770447 \\ Fax: +385 (51) 686166 \\ www.intechopen.com
}

\author{
InTech China \\ Unit 405, Office Block, Hotel Equatorial Shanghai \\ No.65, Yan An Road (West), Shanghai, 200040, China \\ 中国上海市延安西路65号上海国际贵都大饭店办公楼 405 单元 \\ Phone: +86-21-62489820 \\ Fax: +86-21-62489821
}


(C) 2011 The Author(s). Licensee IntechOpen. This chapter is distributed under the terms of the Creative Commons Attribution-NonCommercialShareAlike-3.0 License, which permits use, distribution and reproduction for non-commercial purposes, provided the original is properly cited and derivative works building on this content are distributed under the same license. 